\title{
Costs of Quality in Construction: Can these be reduced through implementation of ISO 9000 ?
}

\author{
N.D. Gunawardena, M.M.P. Wickremarachchi, \\ R.M. Nismy
}

\begin{abstract}
This paper presents the results of two studies carried out to identify costs of quality and causes of poor quality in construction. There are three types of costs of quality: prevention costs, appraisal costs, and failure costs. The failure costs are usually regarded as avoidable and, if minimised through preventive measures, they could lead to substantial reduction in construction costs. The significant causes of non-conformances or poor quality that contribute to failure costs include: low quality of materials; lack of skilled labour; incompetent subcontractors; lack of commitment and capability of site staff; incorrect construction methods; and lack of site supervision. The paper describes how five sub-requirements of the ISO 9001: 2000 standard can minimise the effects of these six causes in order to reduce costs of quality.
\end{abstract}

\section{Introduction}

The effect of poor quality on construction costs can be significant though it is usually overlooked by contractors (Abdul-Rahman, 1995). Due to the present economic conditions and the severe competition in the industry, contractors are forced to review and highly control project costs; at such period of times, they have a tendency to give a low priority to quality due to financial constraints. Ironically, these are the occasions which present the greatest opportunities for organisations to minimise operational losses through quality improvement (Laszlo, 1997).

Contractors often assume that improving the quality of works increases the cost of construction. This view is quite understandable, but it is erroneous; all quality improvement activities do not have higher price tags. Previous studies, such as the one carried out by Roberts (1991) in the construction industry, show that the costs of quality improvement efforts are often out-weighed by financial benefits derived from less defects and reduced rework. The concept called 'Costs of Quality' can be used to shed more light on the financial benefits of effective quality management programmes in contractor organisations.

\section{Costs of Quality (COQ)}

Costs of Quality' is not a new concept. More than three decades ago these were defined as those costs incurred by businesses as a result of product not being designed, produced, or serviced in a perfect manner (Simons, 1970). During early days, however, these costs were defined in terms of poor quality. Subsequent definitions were more comprehensive and covered a wider scope. For example, BS 6143(1992) defines costs of quality as those incurred in ensuring and assuring quality as well as loss incurred when quality' is not achieved.

Quality in construction is directly related to the time and cost associated with the works; poor quality always results in unnecessary time extensions and/or extra costs in rectifying deficiencies. This relationship enables us to use the concept of cost of quality as a measure of costs associated with conformance or non conformance of the product requirements agreed, through contracts, between the contractor and client. Thus the contractor's ability to identify and control quality costs makes the difference between the costly way and beneficial way of achieving quality in construction.

Traditionally quality costs have been classified as (a) prevention costs; (b) appraisal costs; and (c) failure costs (Foster, 1996). They are briefly described below.

\section{Prevention Costs:}

Prevention costs are the costs incurred in an effort to prevent defects from occurring. Which include planning, improving and maintaining a quality system, training and education programmes.

\section{Appraisal Costs:}

Appraisal costs are the costs incurred in identifying which individual projects do not conform to specifications, which include design appraisal, sample tests, and inspections.

\section{Failure Costs:}

The costs of producing non-conformances during design or construction are traditionally known as 
'failure costs'. These include the internal failure costs such as costs for rectification of deficiencies that are detected through appraisal activities by the contractor and the external tailure costs such as claims and sometimes loss of reputation due to deficiencies detected by the client after completion of the works. It has been estimated by Construction Industry Development Board of Singapore (Low and Yeo, 1997) that, an average construction contractor spends $5-10 \%$ of the total project costs in producing non-conforming works and later rectifying them.

Generally, COQ (sometimes referred as 'quality costs') are interrelated and vary with the level of conformance measured in terms of quality requirements. As the level of conformance improves, according to the well-known Lundval-Juran curve, the failure costs decrease and the prevention and appraisal costs increase (Foster, 1996). The curve (see Figure 1) uses two broad categories of costs (Feigenbaum,1983): (a) prevention and appraisal costs and (b) failure costs. Although this general theory can be extended to any specific product. the exact relationship between the level of contormance and the quality costs has not yet been established for construction works. However, it may be possible to vary the prevention and appraisal activities to improve conformance and reduce the total cost of quality, provided that the increase in the prevention and appraisal costs is comparatively less than the corresponding decrease in the failure costs.

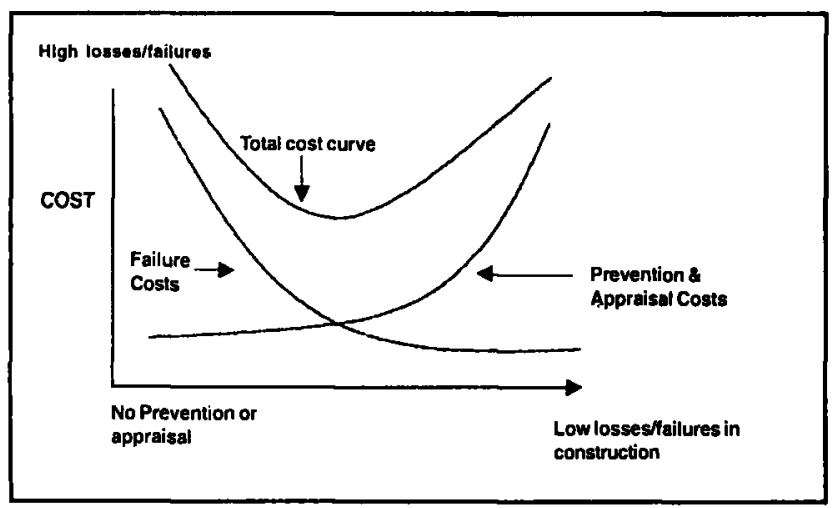

Figure 1: Lundval - Juran curve

The failure costs are usually regarded as avoidable and any approach to reduce quality costs must first tackle them by eliminating causes of nonconformances. This in turn, will lead to substantial reduction in appraisal costs. The prevention costs associated with such approaches are comparatively low and previous research studies suggest that through spending $1 \%$ more in prevention costs, the failure costs can be reduced in the order of $8 \%$ of the construction costs (Roberts, 1991).

The use of the COQ approach for the management and control of quality defects is well established in the manufacturing industry (Hall and Tomkins,
2001). The potential of $C O Q$ concept in the construction industry is only beginning to be realized although there had been related studies in countries such as the USA (Burati et al; 1992), the UK (Abdul-Rahman et al., 1996), in Singapore (Low and Yeo, 1997) and Australia (Love and Li, 2000). However, no similar studies have been conducted in the local construction industry. Therefore, two case studies were undertaken by the authors to get first-hand information on COQ in the local context. As one or two case studies would not represent the entire construction industry, the objective was mainly to compare COQ of a typical project/s with corresponding values obtained from the literature for construction and other sectors.

Two large construction projects were selected for Case Study 1, and Case Study 2, and their quality costs were collected for 18 and 6 months respectively. The quality costs for the projects were collected by personally visiting the sites and going through various cost and other record maintained by the contractors and consultants. Then these costs were expressed as percentage values under three cost categories: (a) prevention and appraisal, (b) failure or non-conformance; and (c) failure due to construction related activities including subcontractors. A comparison of the COQ figures for Case Study 1 and the corresponding values obtained from literature related to other countries is presented in Table 1. (Case study 2 is not presented as the cost data for substantial part of the project could not be collected.)

Table 1: COQ for Case Study and Previous Studies (as $\%$ of Total Value)

\begin{tabular}{|c|c|c|c|c|c|}
\hline 总 & 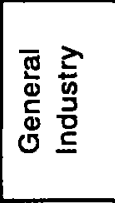 & 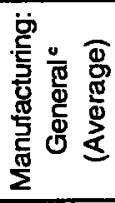 & 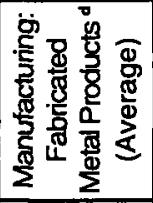 & 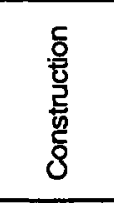 & 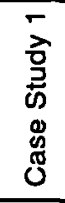 \\
\hline COQ & $10-30$ * & 5.8 & 4.9 & $8-15^{*}$ & 18.4 \\
\hline $\begin{array}{l}\text { Prevention } \\
\& \text { Appraisal } \\
\text { Costs }\end{array}$ & $3-4^{4}$ & 2.1 & 2.2 & - & 1.7 \\
\hline Failure Costs & - & 3.7 & 2.7 & $6-12^{r}$ & 16.7 \\
\hline $\begin{array}{l}\text { Construction } \\
\text { related } \\
\text { failure costs }\end{array}$ & n.r. & n.r. & n.r. & - & 8.6 \\
\hline
\end{tabular}

- Hall and Tomkins (2001); significantly

high upper bound is due to service industries where COQ is usually higher

b Johnson (1995)

c "Quality Cost Survey" (1997)

d Dale and Plunkett (1995)

- Low and Yeo (1998)

1 Burati et al. (1992)

n.r. $=$ not relevant 
Based on the results of different studies, the COQ in construction appears to be higher than manufacturing industry. The COQ for the Case Study 1 is even higher indicting poor quality management; the situation with respect to Case Study 2 is worse than Case Study 1 although it is not reported here as the study period ( 6 months) was too short. The failure costs of the case study (Case Study 1) were also higher than the corresponding values estimated for the construction works and significantly higher than those in manufacturing. The prevention and appraisal costs in terms of total value of work of the case study is relatively lower than the corresponding figures for the other sectors and this perhaps explains the reason for higher $\mathrm{COQ}$ contributed by failure costs $(16.7 \%)$.

Table 2: COQ for Case Study and Previous Studies (as \% of COQ)

\begin{tabular}{|c|c|c|c|c|c|}
\hline 营 & 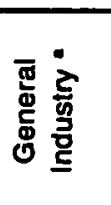 & 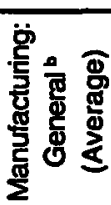 & 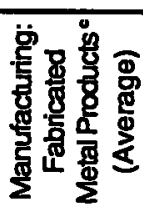 & 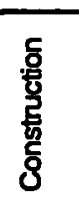 & 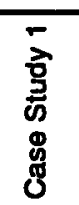 \\
\hline $\begin{array}{l}\text { Prevention } \\
\text { \& Appraisal } \\
\text { Costs }\end{array}$ & $15-30$ & 36.3 & 45.0 & - & 9.3 \\
\hline Failure Costs & $70-85$ & 63.7 & 55.0 & - & 90.7 \\
\hline $\begin{array}{l}\text { Construction } \\
\text { related } \\
\text { failure costs }\end{array}$ & n.r. & n.r. & n.r. & $40^{\circ}$ & 8.6 \\
\hline
\end{tabular}

a Johnson (1995)

"Quality Cost Survey" (1997)

- Dale and Plunkett (1995)

- Approximate. See, BRE (1982)

n.r. $=$ not relevant

The above costs when expressed as percentages of COQ tell a similar story (see Table 2). The performance of the project in Case Study 1 appears to be unsatisfactory as its failure costs are over $90 \%$ of COQ; whereas these for the general industry and other sectors, as reported in literature, are relatively lower. The most important result, however, is the percentage contribution (over $50 \%$ ) made by construction related failures (including the subcontractors) towards total failure costs; this again is a higher value compared to the figure $(40 \%)$ estimated by the Building Research Establishment of the UK (BRE, 1982).

As mentioned earlier, the above case study can be used to understand the level of quality costs in a typical construction project in Sri Lanka, particularly the failure costs, with a view to reduce them. Quality improvement efforts can be substantially reduce failure costs, which according to previous studies (Davis et al., 1989) can be as high as $15 \%$ of the total project costs. It is estimated that spending as little as $1 \%$ more on prevention cost, as much as $80 \%$ of the failure costs could.be saved (Robert, 1991). The exact percentage reduction in failure costs may not be in the same order for local construction projects; yet the figures given above are quite sufficient to understand the magnitude of possible cost savings received through increased preventive measures.

There are several COQ models, which are based on the relationship explained by the Lunvall-Juran curve, for determining quality improvement strategies. Therefore, it would appear that a contractor could use one of these COQ models to his construction projects and then take specific prevention action to reduce failure costs. This is easier said than done. Despite the common underline principles, there are some inherent problems with these models. First, they display wide differences in the application, which may, in many cases, could be misleading and inaccurate (Burgess, 1996); second, some of them have been constructed to persuade the reader the value of prescribed courses of action without being concerned with theoretical justification (Plunkett and Dale, 1988). Further, it is strongly emphasised in the literature that $\mathrm{COQ}$ elements and costing methods must be tailor-made to each particular setting (Johnson, 1995). Having right COQ elements and methods is only part of the work; a successful programme requires the commitment and participation of all employed involved using number of quality management toots and techniques Low and Yeo (1998) identify the following as some of the difficulties in modelling $\mathrm{COQ}$ at site level:

a) Quality cost data are very sensitive as they reveal the inefficiencies of the contractor;

b) Extensive involvement of personnel to implement the cost system which may be not practicable in view of heavy work load of site staff; and

c) Continuous presence of a dedicated person at site all the time

The authors have also experienced similar difficulties, in addition to non-availability of accurate icost records, during the collection of data for the case studies. Therefore, implementation of the available COQ models cannot be recommended for all contractors in Sri Lanka, although there are sufficient case histories to illustrate the success of such approaches in developed countries. However, the insight offered by these models and the case studies are still important in devising suitable quality improvement measures at site level. 
The following sections of this paper describe an alternative approach to reduce failure costs and thereby the costs of quality; it includes two specific actions: (a) identification of causes of poor construction quality; and (b) minimising their effects through sound quality management practices.

\section{Causes of Poor Quality in Construction}

Not all causes of poor quality are construction related. A significant portion of construction failure costs are design related (Abdul-Rahman, et al., 1996; BRE, 1982) although they are beyond the control of the contractor, therefore they are not included in the discussion presented in this section.

In order to identify causes of poor quality of construction a questionnaires survey was carried out recently among construction professionals in the industry (Nismy, 2004). For this purpose, a questionnaire was developed, based on the findings of the previous research studies as well as literature on related work carried out in other countries (Hall and Tomkins, 2001) and Sri Lanka (Dayaratne et al., 2000 and Wikramarachchi, 2002). Thirteen possible causes were identified and included in the questionnaire. These included: 1) low quality of material; 2) incorrect construction method; 3) scarcity of skilled labour; 4) commitment/ motivation of workforce; 5) incompetent subcontractors; 6 ) lack of site supervision; 7) lack of commitment and capacity of site staff; 8 ) lack of co-operation among project parties; 9) poor working conditions; 10) poor weather conditions; 11) inaccurate measuring instruments; 12 ) inadequate Specifications; and 13) lack of proper construction equipment.

Table 3: Causes of Poor Construction Quality

\begin{tabular}{|l|c|c|l|}
\hline \multicolumn{1}{|c|}{ Cause } & $\begin{array}{l}\text { Relative } \\
\text { importance } \\
\text { index }\end{array}$ & Rank & \multicolumn{1}{|c|}{ Problem centre } \\
\hline Low quality of Materials & 0.875 & 1 & Market \\
\hline Incorrect Construction Methods & 0.806 & 2 & Culture/ Management/QS \\
\hline Lack of Site Supervision & 0.806 & 3 & Cullure/,Management QS \\
\hline Lack of Commitment and Capability of site staff & 0.781 & 4 & Cullure/ Management/ QS \\
\hline Inaccurate measuring instruments & 0.748 & 5 & Culture/ Management/ QS \\
\hline Lack of skilled Labour & 0.744 & 6 & Market \\
\hline Incompetent Subcontractors & 0.742 & 7 & Market \\
\hline Lack of proper construction equipment & 0.738 & 8 & Culture/ Management/ QS \\
\hline Lack of co-operation among project parties & 0.706 & 9 & Industry structure \\
\hline Commitment Motivation of workforce & 0.694 & 10 & Culture/ Management/ QS \\
\hline Inadequate Specifications & 0.688 & 11 & Industry structure \\
\hline Poor working conditions & 0.676 & 12 & Culture/ Management/ QS \\
\hline Poor weather conditions & 0.612 & 13 & Other \\
\hline
\end{tabular}

The questionnaires were posted to a random sample of construction contractors in Sri Lanka. In addition, several construction professionals were interviewed to study the prevailing situation of the construction industry with respect to quality aspects at site level. Out of 55 posted questionnaires, 32 completed questionnaires were received with a response rate of approximately $58 \%$. In order to identify the impact of the above causes on the quality of construction it was necessary to rank them in the order of importance. To determine the relative ranking of the causes, the results obtained were then transformed to importance indices based on the formula (Kometa et al., 1994)

\section{Relative importance index $=\frac{\sum w}{\mathrm{AN}}$}

Where $w$ is the weighting given to each cause by the respondent, ranging from 1 to 5 where ' 1 ' is the least important and ' 5 ' is the most important, $A$ is the highest weight (i.e., 5 in the study) and $\mathrm{N}$ is the total number of samples. The relative importance index ranges from 0 to 1 . Table 3 shows the relative importance index of each identified cause.

Seven of the causes analysed are related to company culture, management, or Quality system (QS). Three of them are market related and two are related to the structure of the industry. It is seen that most of the causes, including four of the top most important causes, are within the complete control on contractor organization. The market related causes are not with in the total control, but it appears that the contractors too can control them to a certain extent. Of other causes, 'inadequate specifications' and 'Lack of co-operation among project parties' are industry related and it is unlikely that the contractor could control them in order to achieve construction quality.
The last cause, 'Poor weather conditions'. is generally considered as 'Force majeure' (Dale and Plunkett, 1995); as nothing much can be done, its effects are not further discussed. 
As a part of the questionnaire, it was also inquired as to what causes would significantly affect quality of the works. A Likert scale ranging from 1 (strongly disagree) to $\mathbf{5}$ (Strongly agree) was used for this purpose with an average score of 3 (neutral). Using .the mean values and standard deviations computed from the data, a hypothesis test (t-test) was carried out to identify the causes which were significantly greater than 3 (fig 3.1). For this test, the null hypothesis was taken as $H_{0}: \mu d^{\prime \prime} 3.00$, and the alternative hypothesis, as $\mathrm{H}_{\mathrm{a}}: \mu>3.00$; where $\mu$ was the population mean of the corresponding cause. The t-test was performed at $5 \%$ significance level (alpha $=0.05$ ) and the critical $t$ - value for the sample (size = 32) was taken as 1.69 (Anderson et al., 1990). The results of the hypothesis test are given in Table 4. caused of poor quality. For example, the Cause and Effect Diagram (Ishikawa or Fishbone Diagram) can be used for identifying possible causes of poor quality and Pareto ${ }^{2}$ principle, for ranking them in the order of importance. The combination of these two methods enables one to introduce quality improvement measures in the most effective manner. Drawing on the same lines, it is possible assume that failure costs in construction can be considerably reduced by proper control of the six significant factors identified above. For this purpose, these factors can be further studied in relation to a recognised quality management system such as the ISO 9001: 2000 standard.

Table 4: Hypothesis Test on Causes of Poor Construction Quality

\begin{tabular}{|l|c|l|c|}
\hline \multicolumn{1}{|c|}{ Cause } & Rank & $\begin{array}{l}\text { Relative } \\
\text { importance } \\
\text { index }\end{array}$ & $\begin{array}{c}\text { i - statistic } \\
\text { (sample) }\end{array}$ \\
\hline Low quality of Materials & 1 & 0.875 & 4.358 \\
\hline Incorrect Construction Methods & 2 & 0.806 & 2.643 \\
\hline Lack of Site Supervision & 3 & 0.806 & 3.746 \\
\hline Lack of Commitment and Capability of site staff & 4 & 0.781 & 2.435 \\
\hline Inaccurate measuring instruments & 5 & 0.748 & 1.285 \\
\hline Lack of skilled Labour & 6 & 0.744 & 2.005 \\
\hline Incompetent Subcontractors & 7 & 0.742 & 1.752 \\
\hline Lack of proper construction equipment & 8 & 0.738 & 1.58 \\
\hline Lack of co-operation among project parties & 9 & 0.706 & 1.048 \\
\hline Commitment/ Motivation of workforce & 10 & 0.694 & 1.22 \\
\hline Inadequate Specifications & 11 & 0.688 & 0.72 \\
\hline Poor working conditions & 12 & 0.676 & 0.96 \\
\hline Poor weather conditions & 13 & 0.612 & 0.11 \\
\hline
\end{tabular}

The causes shaded in Table 4, were found to be significantly greater than 3.00 at the given level of significance. According to the results, there were six such causes that significantly affect quality of construction.

Of the causes that significantly affect construction quality, 'Low quality of materials', Lack of skilled labour', and 'incompetent subcontractors' are predominantly market related; the only control the contractors have with respect to these causes is at the point of purchasing materials or services of workers and subcontractors. The other three causes, 'Incorrect construction method', 'Lack of site supervision', and 'Lack of commitment and capability of site staff' are predominantly related to the culture, management, and quality system of the organizations; the contractors, therefore, have total control over them.

Some of the tools and techniques used in quality management offer valuable assistanice in controlling

\section{Using ISO 9001: 2000 to Minimise the Effects of Identified Causes}

ISO 9000 is a series of standards, deveioped by. the International Organization for Standardization (ISO). These standards provide the framework for establishing, documenting, and maintaining asystem that ensure the quality of the processes and the products. The ISO 9000 standards have received a significant acceptance worldwide; over 300,000 companies in more than 100 countries are reported to have adopted the standards since their introduction in 1987. Originally, the series had five main standards: ISO 9000 - guidelines for selection and application; ISO 9001, 9002, and 9003 - quality system models for certification; and ISO $9004-$ guidelines on quality management and quality system elements. These standards have been revised twice, first in 1994 to reflect application in all industries, and then in 2000, which is widely regarded as a better approach than its predecessors in enhancing client satisfaction. 
Most of the largest construction companies in the UK and other European countries and Asian countries such as Singapore and Hong Kong have been certified to ISO 9000 standards since the late 1980s (Kam and Tang, 1997). In many countries such as Australia (Love and $\mathrm{Li}, 2000$ ), clients now require contractors to be ISO 9000 certified. ISO 9000 quality management system in still a new concept for industries in Sri Lanka; there is, however, a growing demand for ISO certification among large construction companies.

There is enough evidence as to how the ISO 9000 quality management system can reduce the costs of doing business. For example, Abdul-Rahman (1997), and Ranasinghe (2002) claim that reduction of operating costs through lower scrap and rework rules s one of important benefit of ISO 9000 quality management system. Based on these findings, it is possible to relate the six significant causes of poor construction quality identified in the previous section, five quality requirements of the ISO 9001 standard. These are: Human Resources; Purchasing; Production and Service Provision; Monitoring and Measurement; and Control of Nonconforming Product. In the following sub-sections, these requirements are briefly discussed to illustrate the ISO 9001 (2000) requirements can be used to minimise the effects of the six significant causes of poor quality.

\section{Human Resources (Clause 6.2)}

This requirement deals with personnel performing construction activities which affect quality of the works. However, its application, for obvious reasons, is limited to those permanently employed by the contractors. The important controls includes:

(a) determination of necessary competence for construction personnel performing work affecting product quality;

(b) provision of training to bring their competence to required levels;

(c) ensuring that personnel are aware of the relevance and importance of their activities and how they contributes to the achievement of the quality objectives of the project.

The two main issues relevant to the discussion presented in this paper are training and motivation of construction personnel to achieve quality of the works. Therefore, this sub-requirement is useful in controlling the adverse effects of, mainly, 'Lack of skilled labour.' 'Incorrect Construction Methods', 'Lack of Site Supervision' and 'Lack of Commitment and capability of site staff'.

\section{Purchasing (Clause 7.4)}

Purchasing requirement deals with three aspects: (a) purchasing process; (b) purchasing information; and (c) verification of purchased product.

The purchasing process is to ensure that the purchased product confirms to specified purchase requirements. In a construction contract, these requirements are given in Contract Documents; of these, the Specifications and details given in the Bills of Quality (BOQ) are the most important. The same process is applicable to purchasing of services as well; subcontractors for example are considered to be suppliers of services to construction contractors. According to the standard, contractors must ensure that suppliers of materials and services are evaluated and only those who have the ability to supply materials or services in accordance with project requirements are selected.

Purchasing information is concerned with proper description of the product. The contractors have to clearly specify the materials in accordance with Specifications and other contract documents. An important point, here, is that the contractor must ensure the adequacy of specified purchase requirements prior to their communication to the supplier. If the material descriptions stated in Specifications and BOQ are not adequate, there is a danger of purchasing low quality material. This can be a difficult task for the contractors as research sludies (Dayaratne, 2000; Nismy, 2004.) have identified some problems with the adequacy of frequently used specifications in Sri Lanka.

The last aspect, verification of purchase product, is necessary for ensuring that purchased materials or services meet specified purchase requirements. This is different to any quality control activity (inspection and testing) on receipt as it is usually carried out before delivery of materials to the site (or subcontractor is employed) to ensure that the supplier has, in fact, complied with specified requirements.

The purchasing requirement in ISO 9001: 2000 can, therefore, be used to minimise the adverse effects of the two causes: Low quality of materials and Incompetent subcontractors. However, it should be pointed out, at this stage, that ISO 9000 cannot address the following two issues as they are related to the market and the structure of the industry:

(a) inadequacy specifications; and

(b) lack of skilled workers in the industry 


\section{Production and Service Provision (Clause 7.5)}

When this requirement is implemented at site level, the contractors can ensure the following with respect to the construction processes:

(a) control of production and service provision

(b) validation of processes for production and service provision

Although there are several other sub requirements listed in ISO 9001:2000 standard under this topic, they are of less important with regards to the significant causes of poor quality identified above.

With the first sub-requirement, control of production and service provision, the contractor ensures that the construction work is carried out under such controlled conditions as:

(i) the availability of information precisely describing the characteristics of the product (mainly the Specifications, $B O Q$ and Construction Drawings);

(ii) the availability of work instructions describing the correct method of construction;

(iii) the use of suitable construction equipment;

(iv) the availability and use of monitoring

. and measuring instruments;

(v) the implementation of monitoring and measurement; and

(vi) the implementation of release (approval) activities.

The second requirement is concerned with the validation of processes used for construction work when the resulting output cannot be verified by subsequent monitoring or measurement. There are many processes used in construction falling into this category; for example, it is not possible to verify the strength of concrete by any monitoring of measurement made on fresh concrete. For such work, where deficiencies become apparent only when the product is in use, the contractor should ensure: validation of the process using a defined criteria; approval of êquipment and qualification of personnel; use of specific methods and procedures; maintenance of records and revalidation if necessary.

If used properly at site level, the above two requirements can minimise adverse effects on quality due to the two causes: Incorrect construction methods and Lack of site supervision.

\section{Monitoring and Measurement (Clause 8.2)}

This is yet another important sub-requirement to ensure conformity of the product, which also includes other sub-requirements such as customer satisfaction and internal audits. The most relevant part of the requirement that the contractors can implement at site level is 'monitoring and measurement of product' which can be applied to materials and work, both in-process and completed. Part of monitoring and measurement of product is carried out at appropriate stages of the product realization explained in the previous section The causes that can be controlled by complying with this requirement are ' low quality of materials' and 'lack of site supervision'.

\section{Control of non-conforming product}

The objective of this sub-requirement is to ensure that materials and works that do not conform to product requirements (as specified in Contract Documents) are identified and controlled to prevent their unintended use or handing over to the client. In construction, this sub-requirement is mainly concerned with taking action to eliminate any detected non-conformities. As this is related to 'monitoring and measurements', the causes that are controlled by it include, 'Low quality of materials' and 'Lack of site supervision'.

Finally, there are about 23 sub-requirements under them; using only five of them as described above will make the contractors' job much easier. This situation can be further explained using the 'Pareto' principle: ISO 9001: 2000 can minimise the effects of most significant causes of poor quality in construction by applying approximately $20 \%$ of its sub-requirements; this way, the requirements given in the standard can be used to reduce Costs of Quality in an effective manner.

\section{Conclusions}

Costs of quality (COQ) in construction are estimated to between 8 and 15 percent according to studies carried out in other countries; case studies undertaken indicate that these in Sri Lanka can be even higher. According to COQ models, there are three types of costs: prevention costs. appraisal costs, and failure costs. The failure costs are usually regarded as avoidable and if minimised through preventive measures, they could lead to substantial reduction in appraisal costs. The prevention costs associated with such approaches are comparatively low and previous research studies suggest that through spending $1 \%$ more in prevention costs, the failure costs can be reduced in the order of $8 \%$ of the construction costs (Roberts, 1991).

Any approach to reduce quality costs must, therefore, identify and eliminate the factors contributing to failure costs or the causes of poor quality. According to local contractors, there are six significant causes of poor construction quality; 
three of them are market related and the rest are related to the culture, management and quality system of the organisations. The results of this study suggest that the effects above six causes can be minimised by adopting about five subrequirements of the ISO 9001: 2000 standard. However, the ISO 9001 standard is a quality management system and it should be applied as a complete system rather than as individual elements or sub-requirements because they are interrelated.

As only few local construction contractors have obtained ISO certification so far (De Silva and Goonatillake, 2001), it may not be possible to assume all other contractors to embrace ISO system in the near future just because of its benefits. However, contractors, not in a position to implement the entire ISO 9001 system, can implement, at least, the most important requirements and reduce costs of quality substantially. The contractors who have got ISO certification can further improve their systems by paying more attention to the five ISO requirements highlighted in this paper.

\section{References}

Abdul-Rahman, H. (1995) Improving Construction Performance with Nonconformance Information. First International Conference on Construction Project Management, January 1995, Singapore, pp 465-477.

Abdul-Rahman.H, Thompson, P.A., and Whyte, I.L.(1996), Capturing the cost of non-conformance on construction sites, International Journal of Quality \& Reliability Management , 13(1), pp 48-60.

Abdul-Rahman, H., (1997), Some observations on the issues of quality cost in construction, International Journal of Quality \& Reliability Management, 14(5), pp 464-481.

Anderson, D.R, Sweeny, D.J, and Williams, T.A, (1990), Statistics for Business and Economics, $4^{\text {th }}$ ed., St. Paul, MN: West Publishing Co. BS 6143, Guide to Economics of Quality, British Standards Institution, London.

Building Research Establishment (1982), Quality in Traditional Housing, London: HMSO.

Burati, J.L., Farrington, J.J. and Ledbetter, W.B., (1992) Causes of quality deviation in design and construction, Journal of Construction Engineering and Management, ASCE, 118(1), pp 34-49.
Burgess, T.F., (1996) Modelling quality-cost dynamics, International Journal of Quality and Reliability Management 13(3), pp 826

Dale, B.G. and Plunkett, J.J., (1995) Quality Costing $2^{\text {nd }}$ edition, Chapman and Hall, London

Dayaratne, M.P.C.J., Alagiyawanna, A.M.A.K., and Tennakoon, N.P. (2000), Quality of Specifications used in Building Construction, Final year Project report, Department of Civil Engineering, Moratuwa, Sri Lanka.

De Silva, G.M.S. and Goonatillake, L, (2001), ISO 9000 Certification - Impact on the output and activities of sample of Sri Lanka companies. Third National Convention on quality Competitiveness through Quality Management, Sri Lanka Association for Quality, Colombo, Sri Lanka, 21 - 22 November.

Feigenbaum, A.V. (1983) Total Quality Control, MC Graw-Hill, New York, NY.

Foster Jr, S.T. (1996), An Examination of the Relationship between Conformance and Quality Related Costs, International Journal of Quality \& Reliability Management, 13 (4), pp 50-63.

Hall, M. and Tomkins, C, (200i), A Cost of Quality Analysis of Building Project: Towards a complete Methodology for Design and Building, Construction Management and Economics, 19(4), pp 727-740.

ISO 9001 (2000) Quality Management Systems Requirements, International Organisation for Standardisation, Geneva.

Johnson, M.A., (1995) The development of measures of the cost of quality for an engineering unit, International Journal of . Quality and Reliability 12(2), pp 86-100.

Kam, C.W. and Tang, S.L, (1997), Development and implementation of quality assurance in public construction works in Singapore and Hong Kong, International Journal of Quality \& Reliability Management, 14(9), pp 90928.

Kometa, S.T, Olomolaiya, P.O, and Harris, F.C, (1994), Attribute of UK construction clients influencing project consultants' performance, Construction Management and Economics, 12(5), pp 433-443. 
Laszlo, G.P.(1997) The role of quality cost in TQM, The TQM Magazine $9(6)$ pp 410 413.

Love, P.D. and Li, H. (2000), Overcoming the problems associated with quality certification, Construction Management and Economics, 18, pp 139-150.

Low, S.P. and Yeo, H.K.C. (1998)

A construction quality costs quantifying system for the building industry, International Journal of Quality Reliability Management, 15(3), pp 329-349.

Nismy, R.M. (2004) The Impact of Contract Documents on Quality Aspect in Building Construction Industry, MSc Thesis, Department of Civil Engineering, University of Moratuwa, Sri Lanka,

Plunkett, J.J and Dale, B.G., (1988) Quality costs, a critique of some economic cost of quality models, International Journal of Production Research, 26(11), pp 1713-26.
Quality cost survey (1997), Quality, June 1997 pp 20-22.

Ranasinghe, H.S.S (2002), Application of ISO 9000 Quality Management Standards in Sri Lanka, MSc Thesis, Department of Management of Technology, University of Moratuwa, Sri Lanka,

Roberts, R, (1991), Quality does not Cost-it pays. Australian Construction Law Repert, 10(4), pp 137-144.

Simmons, D., (1970) Practical Quality Control, Addison-Wesley Publishing Co., Massachusetts.

Wickramarachchi, M.M.P, (2002), A Study on Cost of Quality in Building Projects, MSc Thesis, Department of Civil Engineering, University of Moratuwa, Sri Lanka. 